\title{
APROXIMACIÓN A LA CARACTERIZACIÓN DE EMPRENDEDORES AVALADOS POR EL FONDO EMPRENDER SINCELEJO*
}

\author{
CARMEN ESTELA HERRERA GUERRA** \\ LUZ ALEXANDRA MONTOYA RESTREPO***
}

Recibido 9 de Octubre de 2012 / Enviado para Modificación 10 de Noviembre de 2012/ Aceptado 2 de Diciembre de 2012

\begin{abstract}
RESUMEN
El emprendimiento como alternativa que dinamiza la economía y genera empleo, es considerado campo de investigación desde los años ochenta, fecha desde la cual se encuentra en proceso de validar y legitimar sus teorías a falta de un marco conceptual. Normalmente, los estudios en emprendimiento están direccionados a la empresa, más que a buscar una definición del "Entrepreneur" o emprendedor, término que conserva su origen francés por la inadecuada traducción a otros idiomas. Esto inspiró la presente investigación, a la luz de un enfoque cualitativo y descriptivo, cuyo objetivo es realizar una aproximación a la caracterización de los emprendedores financiados por el Fondo Emprender Sincelejo. Para esto, es realizado una revisión bibliográfica sobre la definición y caracterización en libros y artículos de revistas indexadas por Colciencias; se aplica el instrumento que permite conocer la caracterización del emprendedor, se tabula la información, se grafican los datos; y finalmente se compara con los resultados revelados por el informe del Global Entrepreneurship Monitor - GEM. En conclusión, se pudo identificar que el perfil del emprendedor fondo emprender Sincelejo es: hombre, entre los 25 y 30 años, con un nivel de estudio en pregrado, alerta a las oportunidades y los riesgos que estas representan, innovadores, con ingresos por fuera de su negocio, y tomaron la creación de su empresa como una elección de carrera.
\end{abstract}

\footnotetext{
* Artículo de investigación. Documento resultado de una investigación realizada en el marco de la Maestría en Administración, dentro de la línea de investigación en mercadeo, innovación y competitividad en gestión agropecuaria MILAGRO.

** Candidata a Magister en Administración, Universidad Nacional de Colombia, Contadora pública. Correo Electrónico: cherrera-44@hotmail.com.

*** PhD, Profesora Asociada, Coordinadora Nacional del Concurso docente, Vicerrectora General. Correo Electrónico: lamontoyar@unal.edu.co, Grupo de investigación en mercadeo, innovación y competitividad en gestión agropecuaria MILAGRO.
} 
Palabras clave: Emprendimiento, Marco teórico, Campo de investigación, Emprendedor, Definición, Caracterización, Fondo Emprender, GEM.

\begin{abstract}
Entrepreneurship as an alternative which boosts the economy and creates jobs, is considered research field since the eighties, since which is in the process of validating and legitimizing their theories in the absence of a conceptual framework. Typically, studies in entrepreneurship are routed to the company, rather than to seek a definition of "Entrepreneur" or entrepreneur, a term that retains its French origin by inadequate translation into others languages . This inspired the present investigation, in light of a qualitative and descriptive approach, which aims to make an approach to the characterization of entrepreneurs fondo emprender Sincelejo. For this, we conducted a literature review on the definition and characterization of books and articles in journals indexed by COLCIENCIAS, the instrument is applied to find out the characterization of the entrepreneur, the information is tabulated, graphed data, and finally compared to the results revealed by the report of the Global Entrepreneurship Monitor - GEM. In conclusion, it was identified that the profile of the entrepreneur to fondo emprender Sincelejo are men between 25 and 30 years, with a level of undergraduate study, alert to opportunities, and risks they represent, innovative, outside income of your business, and took the creation of your business as a career choice.
\end{abstract}

Key words: Entrepreneurship, theoretical framework, field of research, Entrepreneur, Definition, Characterization, Fondo emprender, GEM.

Classification Journal Economic Literature (JEL): L26, M1, M13, M14.

\title{
INTRODUCCIÓN
}

El emprendimiento es una estrategia utilizada por países y regiones, dado sus excelentes resultados para disminuir el impacto del desempleo y promover el espíritu emprendedor (1). Este tema ha transcendido las fronteras del conocimiento, pasando de economistas a otras disciplinas del saber que han realizado sus aportes a éste fenómeno buscando legitimarlo como campo de investigación, siendo esto la causa de que no exista un consenso entre los autores de ésta nueva disciplina. 
La definición y caracterización del emprendedor, ha despertado poco interés en las investigaciones, es más usual encontrar publicaciones dedicadas a la actividad y función del emprendedor, que a él como persona y elemento principal de todo el proceso del emprendimiento. Es por esto que el presente documento surge como respuesta al desafío de trabajar un marco teórico a la definición y caracterización del emprendedor, el cual permita obtener como objetivo final el perfil de éxito de los emprendedores fondo emprender Sincelejo.

Para esto, el documento se estructura en tres partes: primero, se elabora el marco teórico a partir de la revisión a la literatura, se recopila y sistematiza los postulados más representativos de los autores encontrados, y se extrae de estos la definición y caracterización del emprendedor. En segundo lugar, se aplica la encuesta con la cual busca aproximarse a la caracterización. Y en tercer lugar, los resultados obtenidos se validan con los revelados por el GEM Colombia Caribe 2010. Al final, se presenta unas breves conclusiones.

\section{METODOLOGÍA}

Esta investigación se abordó desde un enfoque metodológico cualitativo y descriptivo, cuyo objetivo es reconocer antes que explicar, las características presentes en los emprendedores que lograron financiar sus planes de negocios a través del fondo emprender. Para esto, se utilizó la estrategia metodológica planteada por Quivy y Campenhoudt, en el manual de investigación de ciencias sociales, basada en tres componentes fundamentales: La ruptura, la estructuración, y la comprobación.

En la primera etapa, se selecciona el terreno de estudio, Emprendimiento, se realizan las lecturas exploratorias, y se determina que la problemática a investigar, es el emprendedor. La segunda fase, inicia con la estructuración teórica realizada, y se eligió los postulados del GEM para validar la información. En el último componente se realizó el trabajo de campo, se elaboró y aplicó el instrumento de recolección, se analizó la información recopilada, se comparan los resultados obtenidos, con los resultados esperados; y finalmente se llegan a las conclusiones y nuevos aportes al conocimiento (Figura No. 1). 
FIGURA 1. METODOLOGÍA ADAPTADA

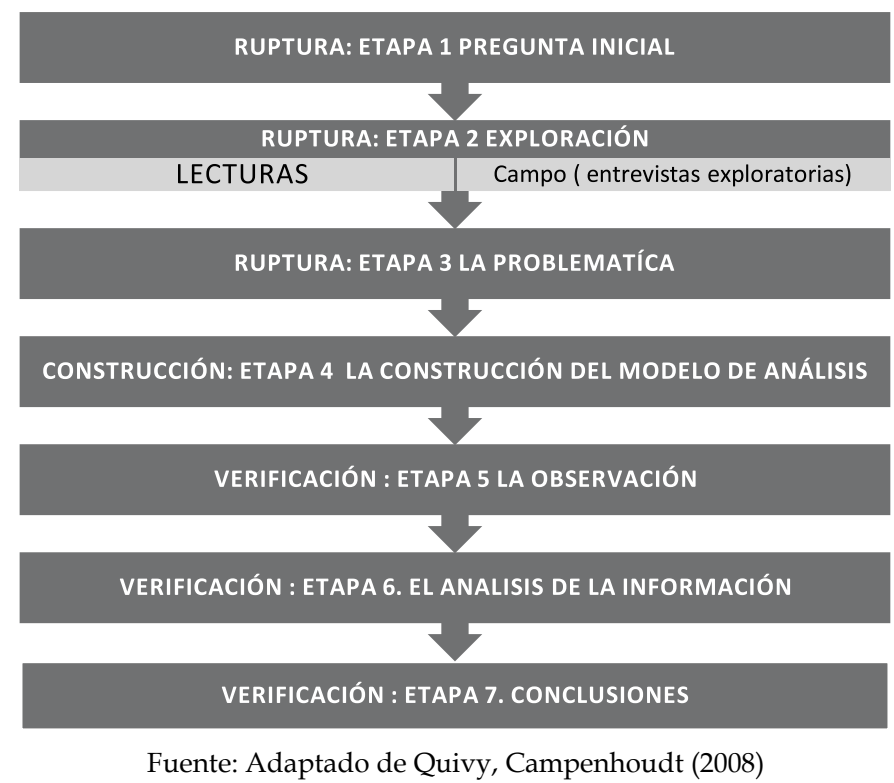

Los instrumentos utilizados para la recolección de datos fueron los siguientes:

- Fuentes secundarias, se consultaron las bases de datos electrónicas: Emerald, Jstor, Ebsco Hot, E-libro, para obtener publicaciones de artículos y revistas especializadas. También se utilizó libros impresos, información de páginas web, y memorias de congresos.

- Se investigó en la unidad de emprendimiento del SENA, la información básica de los emprendedores avalados por el fondo emprender Sincelejo.

- El instrumento metodológico utilizado fue la encuesta, basada en las dimensiones presentadas por el GEM Colombia Caribe 2010.

- Información de fuentes primarias, obtenidas directamente de los emprendedores financiados por el Fondo Emprender.

Método: El trabajo de campo inicia con la información obtenida de la unidad de emprendimiento SENA, la cual fue validada con la información por convocatorias de la página web del fondo emprender. Una vez identificado todos los emprendedores financiados por este fondo para el departamento de Sucre (62 proyectos), se clasificó por municipio, y fueron seleccionados los de la ciudad de Sincelejo. Esto arrojó como resultado una población potencial de 22 personas. 
Estos emprendedores fueron contactados por correo electrónico, llamadas a teléfonos fijos y móviles, así como visitas al lugar de su residencia u oficina. Esto permitió confirmar la participación en la investigación de 17 personas, así como la imposibilidad de los 5 restantes por presentar dificultades en la ubicación. Esta situación determinó que el estudio fuera realizado con 17 emprendedores.

La encuesta es elaborada de forma simultánea a la selección de las personas sujeto del presente estudio. El instrumento fue diseñado con preguntas como la edad, género, formación académica, nivel de ingresos, entre otros aspectos que se encontraban enmarcados en la caracterización revelada por el GEM para la ciudad de Sincelejo. La estructura de la encuesta permitió una pronta respuesta por parte de los emprendedores, los cuales accedieron sin ningún inconveniente.

Una vez recopilada la información, esta se sistematiza utilizando la herramienta de Excel, la cual permitió graficar esta información para cada una de las situaciones encontradas. Al final se realizó la contrastación entre los resultados que presentó la encuesta con cada una de las dimensiones propuestas por el GEM para Sincelejo.

\section{MARCO TEÓRICO DEL EMPRENDIMIENTO}

El emprendimiento tiene varias acepciones:

- De acuerdo a las leyes colombianas (1) es una manera de pensar y actuar orientada hacia la creación de riqueza, una forma de pensar, razonar y actuar centrada en las oportunidades, planteada con visión global y llevada a cabo mediante un liderazgo equilibrado, y la gestión de un riesgo calculado, su resultado es la creación de valor que beneficia a la empresa, la economía y la sociedad.

- Para Shane y Venkataraman (2) se define como el campo académico donde se evalúa, cómo, por quién, y con qué efectos, se crean oportunidades de futuros bienes y servicios. En consecuencia, el campo implica el estudio de las fuentes de oportunidades, los procesos de descubrimiento, evaluación y la explotación de las oportunidades, y los individuos.

- Entantoque para Gibbs(3) la cultura empresarial es como el conjunto de valores, creencias y actitudes que refuerzan la convicción de la validez del esfuerzo independiente como medio de éxito y autosatisfacción. La cultura empresarial les permite a muchas personas, ser empresarios aun sin tener negocios con finalidad económica y por esto es posible 
ser, y actuar como empresarios en los sectores cívicos, religiosos, culturales, filosóficos, políticos, científicos, educativos, igual que en los sectores económicamente productivos.

- De otro lado, Timmons $(4 ; 5)$ es la habilidad de crear y construir algo a partir de prácticamente nada. El espíritu empresarial (Entrepreneurship) es una forma de pensar, razonar y actuar que se basa en una obsesión por la oportunidad, en un enfoque holístico, en un liderazgo balanceado. En el corazón de este proceso, está la creación y el crecimiento de la oportunidad, seguida por el deseo y la iniciativa para aprovechar.

Un dato importante para tener en cuenta al momento de revisar la literatura es que el emprendimiento, espíritu empresarial, capacidad emprendedora, y entrepreneurship, son sinónimos entre sí, utilizados de esta forma por diversos autores. Para este documento, el emprendimiento es entendido como la capacidad y habilidad para construir una organización (con o sin ánimo de lucro), la cual es en términos de Dávila (6) un ente social, creado intencionalmente para el logro de determinados objetivos, mediante el trabajo humano, y recursos materiales. La cual se encuentra influenciada por los factores del entorno $(7 ; 8 ; 9)$.

Se resalta el hecho que el emprendimiento es una estrategia utilizada por los países para activar la economía $(9 ; 10)$ y generar empleo $(9 ; 11 ; 12 ; 13$; $14 ; 15)$. Lo que ha generado la creación de programas que apoyen esta actividad $(7 ; 9 ; 16 ; 17 ; 18)$, tal como el venture capital, que permite poner en contacto al emprendedor con su financiador $(7 ; 19 ; 20 ; 21 ; 22 ; 23)$.

Por la relevancia del tema, se ha despertado el interés en los investigadores de otras disciplinas $(2 ; 9 ; 24 ; 25)$, y académicos $(26 ; 27)$, lo que ha permitido que el emprendimiento se convierta en un importante campo de investigación científica $(9 ; 20 ; 21)$, sin que esto signifique la existencia de una sola teoría que defina y explique este fenómeno $(12 ; 14 ; 17)$.

En consecuencia, sus postulados originan un conocimiento fragmentado, con débiles fundamentos conceptuales, y sin un sólido marco conceptual $(2 ; 18 ; 20 ; 21 ; 28)$. Lo que la insta a luchar para definirse como campo investigativo, que legitima sus teorías (29), evidenciándose esta debilidad al momento de revisar la literatura (20).

Algunos estudios bibliométricos que han mostrado su interés en conocer la producción literaria de este campo son: Kent (30), Van y Versloot (31), Matiz (24), Kuskova (32), y Sánchez y Gutiérrez (18). Razón por la cual el 
emprendimiento se postula como una promesa en el campo dela investigación $(2 ; 25)$, donde aún existe mucho trabajo por hacer, como es el caso de producir un cuerpo sistemático de teorías, que den legitimidad a todos sus postulados, y contribuya a un gran aporte en la ciencia de la gestión.

\section{EL OBJETO DE ESTUDIO DEL EMPRENDIMIENTO}

En un campo de investigación científica se identifica el objeto de estudio, en el caso del emprendimiento, no existe un acuerdo acerca del objeto de investigación, dada la complejidad que fue tomando el asunto a lo largo del tiempo (24). Por ello, autores proponen analizar al emprendedor: partiendo de las actividades realizadas (33); por las habilidades que demuestren (34), o por la toma de decisión para iniciar su proyecto $(11 ; 16)$.

Por lo anterior, resulta importante definir al emprendedor, dado que existe una variedad de aportaciones sobre este tema (35). La acción de emprender, posee múltiples acepciones, pero todos coinciden en su origen francés: entreprendre, que significa "encargarse de" $(13 ; 36 ; 37 ; 38)$.

Diferentes enfoques investigativos definen al emprendedor a partir de los rasgos psicológicos y biográficos del entorno $(19 ; 20 ; 39)$, otros simplemente tienen en cuenta las características que deben tener las personas (40). Pero, está demostrado que el emprendimiento está relacionado con una forma de comportamiento, que puede ser cambiado y aprendido (36), como consecuencia de las diferentes reacciones al momento de tomar una decisión (41), y el significado y valor que le aplica al contexto en particular (23), invalidando de esta forma las recetas simplistas (26).

\section{ALGUNOS POSTULADOS ACERCA DEL EMPRENDEDOR}

Richard Cantillon (1680-1734): El emprendedor toma la responsabilidad de poner en marcha y llevar a término un proyecto (27); toma el riesgo de comprar a determinados precios y vender a precios inciertos $(20 ; 37 ; 39$; 42), combinando los factores (43).

Adam Smith (1723-1790): Es el "business management", haciendo referencia a las "fuerzas externas". (37). Es un trabajador superior con innovación (42).

Jean-Baptiste Say (1767-1832): Es el protagonista del desarrollo económico (20); agente productivo que compra a los demás, realiza combinaciones, y genera un producto $(11 ; 43)$; individuo líder, previsor, tomador de riesgos 
y evaluador de proyectos, que moviliza recursos desde una zona de bajo rendimiento a una de alta productividad $(37 ; 39 ; 42)$.

John Stuart Mill (1806-1873): Requiere de habilidades no comunes, lamentó la inexistencia de una palabra en el idioma inglés que tenga el mismo significado que el término "entrepreneur" en francés $(37 ; 39)$.

Alfred Marshall (1842-1924): Poseedor de características propias de un trabajador cualificado - gerente $(39 ; 42)$; actuando en condiciones de incertidumbre, por falta de información (37).

Max Weber (1864-1920): Líder y trabajador superior (carismático), con ética, mentalidad y código de conducta diferente, que lo impulsa a multiplicar la riqueza (42).

Ludwig von Mises (1881-1973): Especular en situación de incertidumbre, respondiendo a las señales del mercado con respecto a precios, ganancias y pérdidas $(36 ; 38 ; 44)$. Posee cualidades de imaginación, audacia y sorpresa (44); poseer tres características esenciales: es evaluador (calcula beneficios y costos), es empresario (construye decisiones para utilizar los factores), y "soporta" la incertidumbre (37).

Frank Knight (1885-1897): Es la persona que percibe los riesgos asegurables y la incertidumbre no asegurable, por tanto afirma que no es tomador de riesgos (42), por su parte Kirzner (44), indica que si toma decisiones bajo riesgo, pero con la ausencia de imaginación y audacia. Valdaliso y López (39), indica que las capacidades son innatas y el conocimiento mejora con la experiencia.

Joseph Alois Schumpeter (1883-1950): El emprendedor posee aptitudes no rutinarias que solo las tienen pocas personas, para crear un nuevo producto $(34 ; 37 ; 38 ; 39 ; 45 ; 46 ; 47)$. Esta persona debe ser brillante, imaginativo, innovador atrevido, lleno de recursos, iniciador del cambio y generador de nuevas oportunidades $(36 ; 48)$; es más que creatividad o invención, es innovar mediante la introducción de nuevos productos o mejora de los existentes $(27 ; 49)$, perturba el equilibrio del mercado con su innovación (20), llevándola al mercado, venciendo las dificultades, y prolongando el éxito en el tiempo $(11 ; 47)$.

Freidrich Hayek (1899-1992): Es un participante del mercado con mayor información, que le permite identificar oportunidades, y estar listo para las sorpresas (44), es ágil, captador e informado (27). 
Peter Drucker (1909-2005): Define al entrepreneur como un empresario innovador, sin que esto signifique que todo aquel que abra un pequeño negocio y corra riesgos, sea innovador y represente un emprendimiento (27; 37), definiendo este último como una conducta, más que un rasgo del carácter (11).

David McClelland (1917-1998): Define al emprendedor como el que ejerce el control sobre los medios de producción, obteniendo su propio ingreso (11). Sus características son: comportamiento especial e interés por actividades que implican riesgo y prestigio (27).

Israel Kirzner (1930-): Es el sujeto que descubre en el mundo de conocimiento imperfecto, una oportunidad que otros no han percibido (44; 46), tiene habilidades para identificar cuando un nuevo producto es aceptado por el cliente, y cuando un nuevo método de producción es percibido por él y desconocido para los demás $(34 ; 36 ; 38 ; 42)$; tiene la ventaja de conocer las imperfecciones del mercado (20).

Karl H. Vesper (1934-): Presentó varias definiciones, de acuerdo a las distintas profesiones: para los economista, persona que reúne recursos, mano de obra, materiales, y otros activos para generar productos; para el empresario, es un competidor agresivo y una amenaza o un aliado; para algunos políticos, es un rebelde, descarriado y muy difícil de controlar; para un filósofo capitalista, es una persona que crea riquezas para él y para otros" (11).

Robert Ronstadt (1936-): Individuos que asumen los principales riesgos en términos de capital, tiempo y compromiso para ofrecer sus productos (11). Cada emprendedor es único, por lo que no se debe buscar un perfil psicológico estandarizado (47).

Howard H. Stevenson (1941-): Define al emprendedor como «un individuo que persigue la oportunidad sin tener en cuenta los recursos que tiene bajo su control» (11), emprendedor es más que crear la empresa, es innovación en el producto, en la organización o en la producción $(20 ; 36 ; 37)$. Detecta oportunidades y tiene la capacidad de ponerlas en marcha, a pesar de no contar con los recursos (27).

Daniel Goleman (1947-): Creador de un nuevo concepto aplicado al emprendedor, denominado "Inteligencia Emocional", la cual promueve la excelencia personal y profesional, niveles superiores de liderazgo, eficiencia, autoconocimiento, autoestima, autocontrol, compromiso, 
integridad, habilidades comunicativas, empatía, iniciativa, adaptabilidad y persuasión (40).

Jeffry A. Timmons (1973-): Persona con habilidad de crear y construir algo a partir de casi nada (47), tomador de riesgos calculados, evita el error, percibe oportunidades, controla los recursos, que normalmente pertenecen a otra persona (11).

Escuelas de pensamiento, según Fonrouge 2002 (42; 52):

a) Escuela psicológica: Está relacionado con ciertos atributos psicológicos de la personalidad, el proceso cognitivo, y otras las circunstancias $(42 ; 50)$. Pese a que las características personológico se han desacreditado (50).

b) Escuela comportamental: Son el conjunto de actividades en marcha, para crear una organización, un gusto por el riesgo y un sentimiento por controlar su destino $(33 ; 42)$.

c) Escuela Económica: Toma decisiones intuitivas, coordinando los recursos escasos (42), siendo el resultado de acuerdo al juicio del emprendedor (27), para ello es necesario que la persona disponga de diferentes conceptos acerca del valor de los recursos para hacer que la oportunidad sea rentable (2).

d) Escuela de procesos: Es quien desarrolla oportunidades y las explota mediante la creación de una organización (21; 42); sin que se afecte por los recursos disponibles (27), iniciando como un acto de voluntad, mediante un proceso holístico, dinámico, único, e influenciado por variables que condicionan su resultado (21).

Para la legislación Colombiana (1): Es una persona con capacidad de innovar, entendida esta como la capacidad de generar bienes y servicios de una forma creativa, metódica, ética, responsable y efectiva.

El Global Entrepreneurship Monitor - GEM (51): Utiliza tres tipologías para los emprendedores de acuerdo a la Nueva Actividad Empresarial (TEA): empresario naciente (con 3 meses de duración), empresario nuevo (de 4 meses a 42 meses), y empresario establecido (de 42 meses en adelante) (52). Caracteriza a los emprendedores de acuerdo al entorno cultural del país y región, y los compara con la misma actividad en el resto de países miembros. En este análisis aplican los postulados de autores como McClelland, para identificar la motivación del emprendedor al momento de crear la empresa. 
Las investigaciones de percepciones de los ejecutivos: Describen al emprendedor en términos como: innovador, flexible, dinámico, capaz de asumir riesgos, creativo, y orientado al crecimiento $(36 ; 38)$.

La prensa popular: También ha escrito extensamente sobre las características psicológicas de los empresarios, entendiendo a estos como "alguien que comienza su propio negocio con éxito, lo que algunos no hacen" $(20 ; 36 ; 38)$.

Una vez presentados los autores con sus planteamientos, se evidencia que no existe consenso en todos ellos, cada uno define y caracteriza al emprendedor desde su perspectiva, y de acuerdo a las condiciones de la época, así mismo sucede con el enfoque. Es notorio que las nuevas investigaciones dejan a un lado el pensamiento simplista, de buscar una receta aplicable a todos, para entrar a un pensamiento sistémico, en donde el todo es más que la suma de las partes, donde las redes del ecosistema, el contexto cultural, y demás factores del entorno, afectan y define la actuación de cada uno.

Para el presente artículo, el emprendedor es definido como la persona, presente en una red del sistema complejo, afectada por factores internos y externos, que busca crear una empresa, con la posibilidad de éxito y fracaso en todo el proceso, así mismo se puede inferir que un emprendedor debe tener el siguiente perfil: individuo con capacidad de adaptabilidad y flexibilidad a los cambios; con innovación, ingenio y creativa para desarrollar nuevos productos, proceso y la misma organización; persistente al fracaso, tomador de riesgos asegurables, y alerta a las oportunidades que presenta el mercado; transformadora de recursos, ambientes y escenarios, que permitan mejorar la calidad de vida de sí mismo y sus empleados. Sin que estas conclusiones se conviertan en una receta mágica que garantice el éxito a todos.

\section{APROXIMACIÓN A LA CARACTERIZACIÓN DE EMPRENDEDORES FONDO EMPRENDER SINCELEJO}

El interés de la presente investigación es conocer el perfil de éxito que posee un emprendedor, cuyo proyecto fue financiado mediante la red de emprendimiento fondo emprender Sincelejo. La caracterización, permite identificar las cualidades y habilidades que poseen los emprendedores, lo cual coadyuva al logro del objetivo propuesto. De igual forma, la caracterización ha sido utilizada en investigaciones, como opción de 
grado, en artículos de revistas científicas especializadas, y en memorias de congresos nacionales e internacional $(38 ; 43 ; 53)$.

Se toma como referencia a Sincelejo, Por dos motivos importantes: el primero, por el impacto económico y social que representa el emprendimiento en ésta región, la tasa de desempleo en Sincelejo es 13,5\%, muy por encima de la tasa nacional con el $11,3 \%{ }^{1}$, y en segundo lugar, la ventaja comparativa que posee la ubicación geográfica de Sincelejo, al ser considerado por el Banco Mundial, Doing Business en Colombia, Bogotá $2010^{2}$, como el cuarto lugar con mejor facilidad para hacer negocios.

Los emprendedores en Sincelejo, disponen de cuatro unidades de emprendimiento para obtener asesorías en la elaboración de su plan de negocios, estas son: Centro de la Innovación, la Tecnología y los Servicios (SENA - Sucre), Universidad de Sucre (UNISUCRE), Corporación Incubadora de Empresas de Sucre (Incubar Sucre), y Corporación Universitaria del Caribe (CECAR). (http://www.fondoemprender. com/unidades.asp). Una vez, se concrete el proyecto, este debe buscar su financiación en las redes de emprendimientos disponibles para ello: Fomipyme, fondo emprender, cajas de compensación, ventures, red de emprendedores bavarias, entre otros.

De las cuatro opciones presentadas, la más relevante y representativa es el Fondo Emprender, por ser parte del plan de desarrollo 2010 - 2014 del presidente de la república Juan Manuel Santos (56), con el cual tiene grandes expectativas de activar la productividad nacional, antes que el empleo o autoempleo, a través de los incentivos económicos ofrecidos a bachilleres y profesionales de postgrado ${ }^{3}$, que cumplan como meta la creación de nuevas empresas motivadas por la oportunidad.

El fondo emprende (57), fue creado por el gobierno nacional con la Ley 789 de 2002, como una cuenta independiente y especial adscrita al SENA, para financiar iniciativas empresariales que provengan y sean desarrolladas por alumnos del SENA, estudiantes que se encuentren cursando los dos (2) últimos semestres en un programa de educación superior reconocido por el estado, de conformidad con las Leyes 30 de 1992 y 115 de 1994, profesionales universitarios que hayan concluido materias dentro de los últimos doce (12) meses, estudiantes o egresados que se encuentren

\footnotetext{
${ }^{1}$ (54) Informe presentado por el Departamento Administrativo Nacional de Estadísticas DANE en la gran encuesta integrada de hogares - Octubre 2010.

${ }^{2}$ (55) Citado por el informe del perfil económico por departamento realizado por el Ministerio de Comercio, Industria y Turismo.

${ }^{3}$ Refiriéndose al estudio de Global Entrepreneurship Monitor - GEM Colombia 2009.
} 
cursando especialización o maestría, y que hayan culminado y obtenido la certificación dentro de los últimos 12 meses.

Según información contenida en el plan nacional de desarrollo (56), el fondo emprender desde su creación ha realizado nueve convocatorias nacionales, 58 convocatorias regionales en asocio con entes territoriales, ha cofinanciado 2.135 proyectos con recursos cercanos a los $\$ 117.000$ millones de pesos. Es de anotar, que aunque los participantes conocen de ante mano la estructura del plan de negocios publicada en su página web, no todos los proyectos pasan la etapa de evaluación y asignación de recursos.

\section{APROXIMACIÓN AL PERFIL DE ÉXITO}

Con la información contenida en la página web del Fondo Emprender, y la obtenida de la unidad de emprendimiento SENA, se pudo observar que durante las 10 convocatorias realizadas entre los años 2002 al 2011, el Departamento de Sucre obtuvo 62 proyectos aprobados, y de estos 22 pertenecen al municipio de Sincelejo.

Una vez analizada la situación de estos 22 emprendedores se encontró: 1 no realizó la ejecución de los recursos para el plan de negocios; 2 llegaron a la tercera fase de ejecución, pero actualmente se encuentran en proceso jurídico; 2 culminaron el proyecto a satisfacción, pero se encuentran dedicados a otra actividad fuera de la ciudad; y los 17 restantes son empresas activas, los cuales fueron quienes participaron de la encuesta.

El instrumento utilizado, está basado en la caracterización propuesta por el GEM 2010 para la ciudad de Sincelejo. Los resultados de la encuesta son analizados frente a estudios similares, los cuales se revelan en las siguientes figuras:

\section{FIGURA No. 2. AÑO DE CONSTITUCIÓN DE LA EMPRESA}

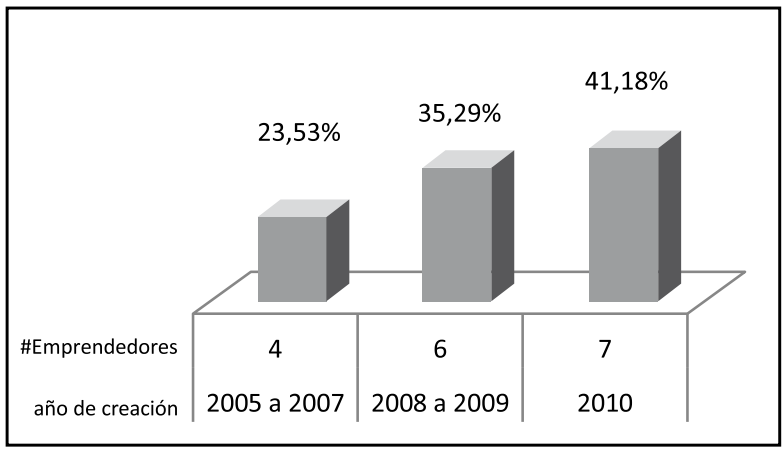

Fuente: adaptado del GEM Colombia Caribe 2010, Elaboración autoras. 
La mayoría se encuentran en la etapa de empresas nuevas o baby business, con duración entre 3 y 42 meses de funcionamiento según el GEM (17; 43). Se observa un aumento en el ciclo de vida de las empresas durante el primer año de vida, donde se presenta la mayor tasa de mortalidad (52).

FIGURA No. 3. SOSTENIBILIDAD DE LA EMPRESA

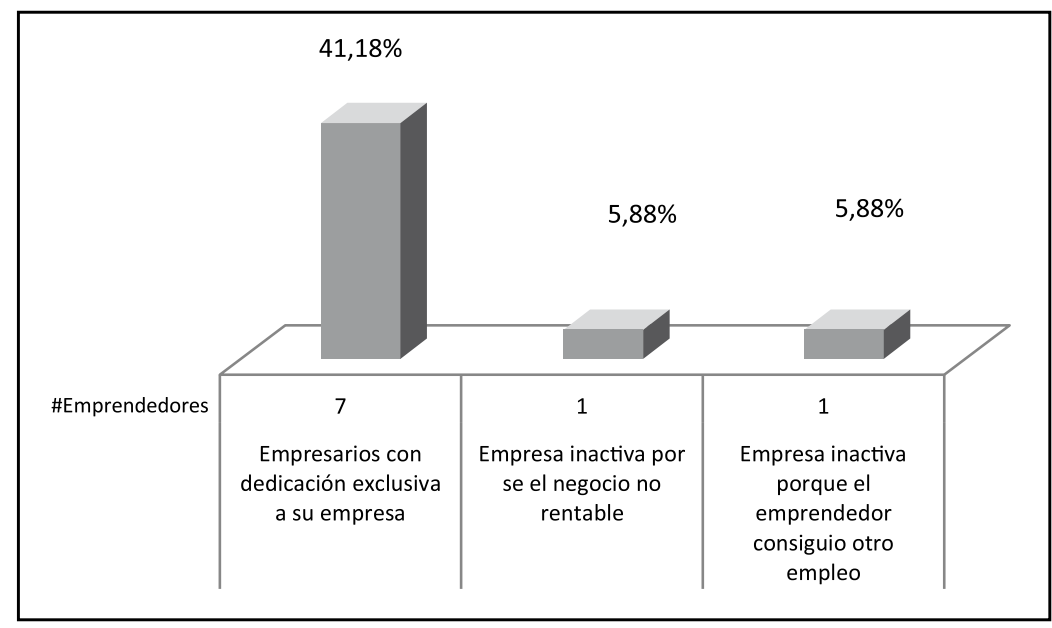

Fuente adaptado del GEM Colombia Caribe 2010, Elaboración autoras.

Estos emprendedores en su mayoría están en el proceso de búsqueda de recursos para la consolidación y establecimiento de la empresa (43). Por lo tanto, no tienen una dedicación exclusiva a la empresa constituida, sino que obtienen ingresos adicionales del ejercicio de su profesión.

\section{FIGURA No. 4. MOTIVACIÓN PARA LA CREACIÓN DE LA EMPRESA}

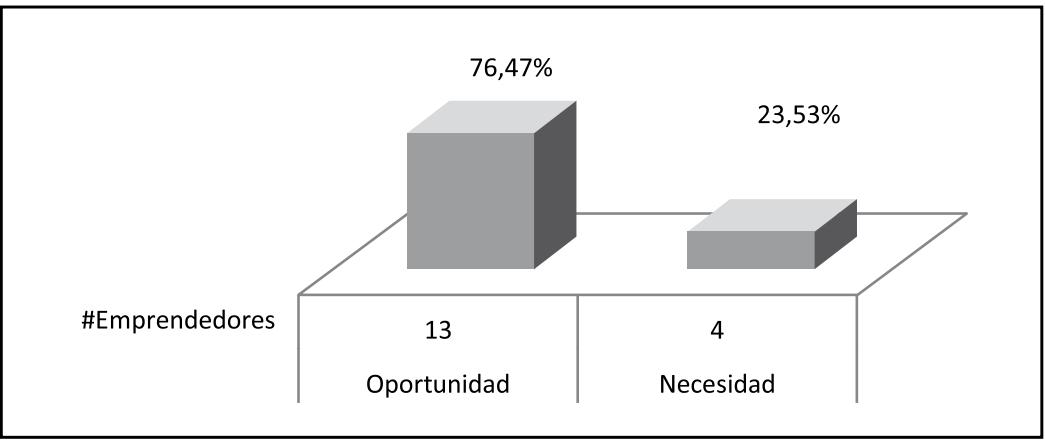

Fuente adaptado del GEM Colombia Caribe 2010, Elaboración autoras.

Estos emprendedores percibieron y aprovecharon una oportunidad que otros no vieron, permitiendo usar de forma eficiente los recursos, que más tarde le permitían construir su empresa (43). 
FIGURA No. 5. GÉNERO

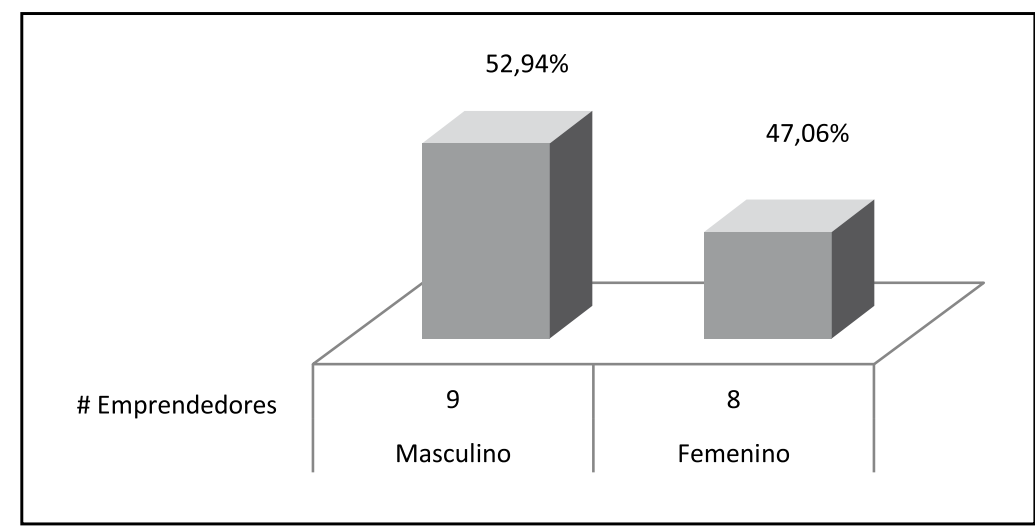

Fuente adaptado del GEM Colombia Caribe 2010, Elaboración autoras.

Los factores que influyen al momento de tomar la iniciativa de emprender una empresa en el género femenino y masculino tienden a ser iguales. Pero, a pesar de estas similitudes, el porcentaje de participación de las mujeres es inferior frente al de los hombres (58).

\section{FIGURA No. 6. EDAD}

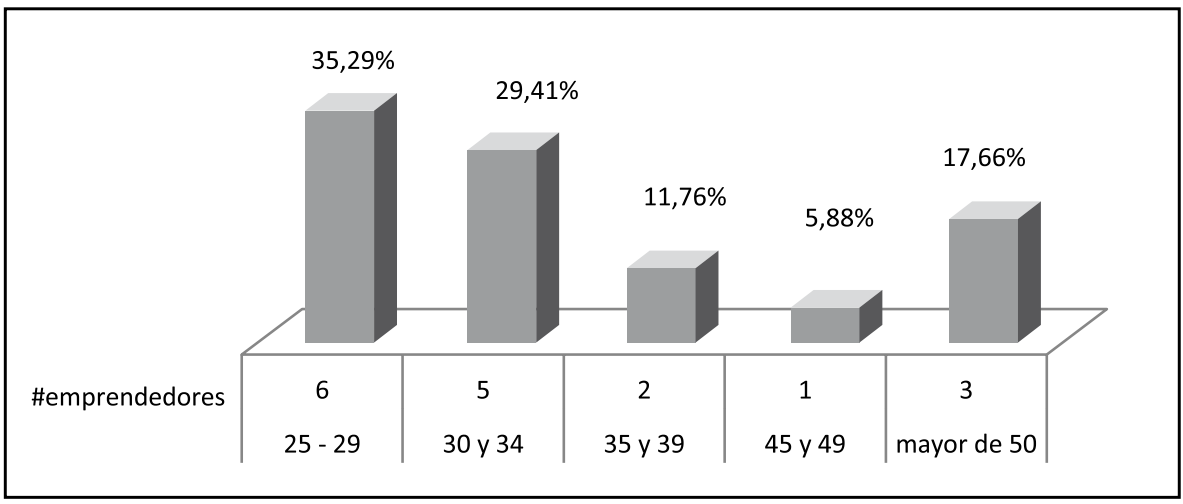

Fuente adaptado del GEM Colombia Caribe 2010, Elaboración autoras.

Estos emprendedores se encuentran en un rango de edad entre 25 a 29 años, lo cual es explicado por otros estudios, donde se destacan que a menor edad, menor es el miedo al fracaso, aspecto que se revierte cuando llega la mayoría de edad (17). 


\section{FIGURA No. 7. FORMACIÓN ACADÉMICA}

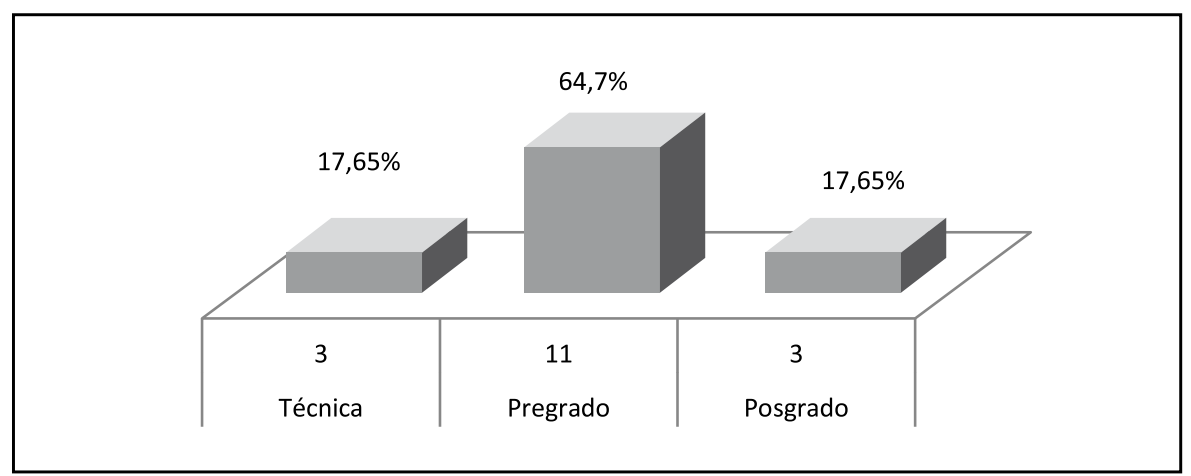

Fuente adaptado del GEM Colombia Caribe 2010, Elaboración autoras.

Dado los requisitos educativos exigidos en las convocatorias del fondo emprender $(56 ; 57)$, la mayoría de los emprendedores pertenecen al grupo de profesionales universitarios sin especializaciones.

\section{FIGURA No. 8. INGRESO MENSUAL}

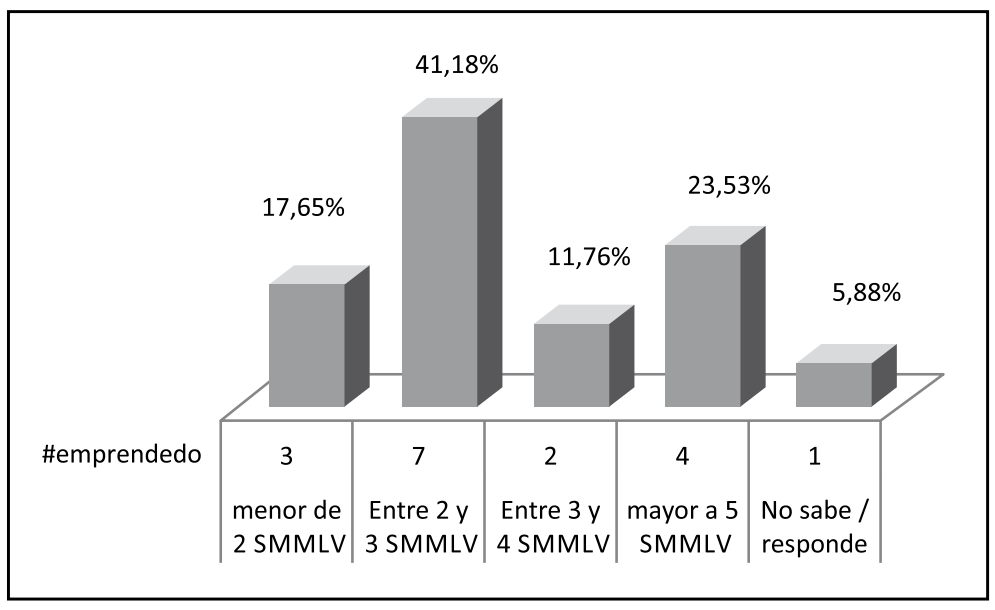

Fuente adaptado del GEM Colombia Caribe 2010, Elaboración autoras.

En Colombia el salario mínimo mensual legal vigente - SMMLV para el año 2012, es de $\$ 566,700$, la mayoría de emprendedores obtienen ingresos por 3 salarios mínimos. Esto se explica por la alta tasa de desempleo en Sincelejo (54), y el surgimiento de muchos empresarios de supervivencia (17). 


\section{FIGURA No. 9. CONOCIÓ A ALGUIEN QUE TUVO NEGOCIO}

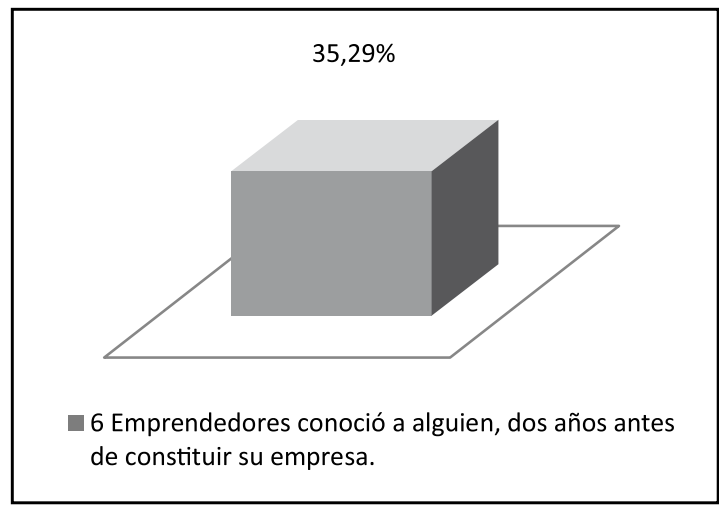

Fuente adaptado del GEM Colombia Caribe 2010, Elaboración autoras.

Solo 6 emprendedores afirmaron haber conocido a alguien antes de crear su empresa. El resto se inclinó por la formación recibida en emprendimiento durante sus estudios académicos, junto con su propia iniciativa empresarial.

\section{FIGURA No. 10. INFLUENCIA EN LA DECISIÓN DE CREAR LA EMPRESA}

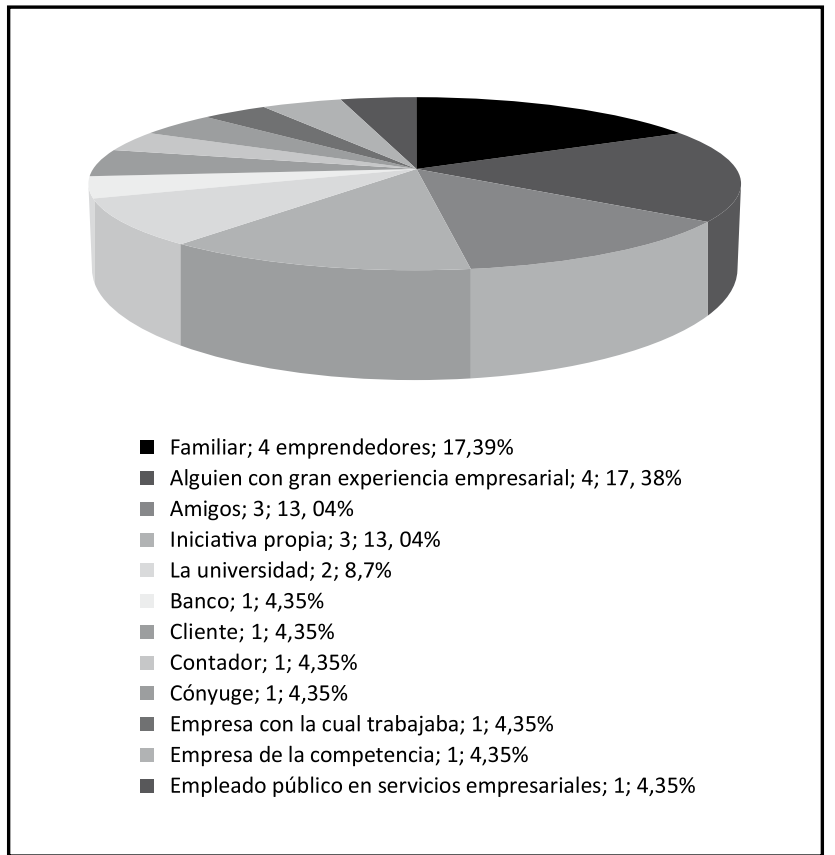

Fuente: adaptado del GEM Colombia Caribe 2010, Elaboración autoras. 
El hecho de participar de una amplia red de emprendimiento, en su hogar, universidades, lugar de trabajo, entre otros, fueron factores que influenciaron en la constitución de la empresa (43).

\section{FIGURA No. 11. ACTITUD FRENTE LA GENERACIÓN DE EMPLEO}

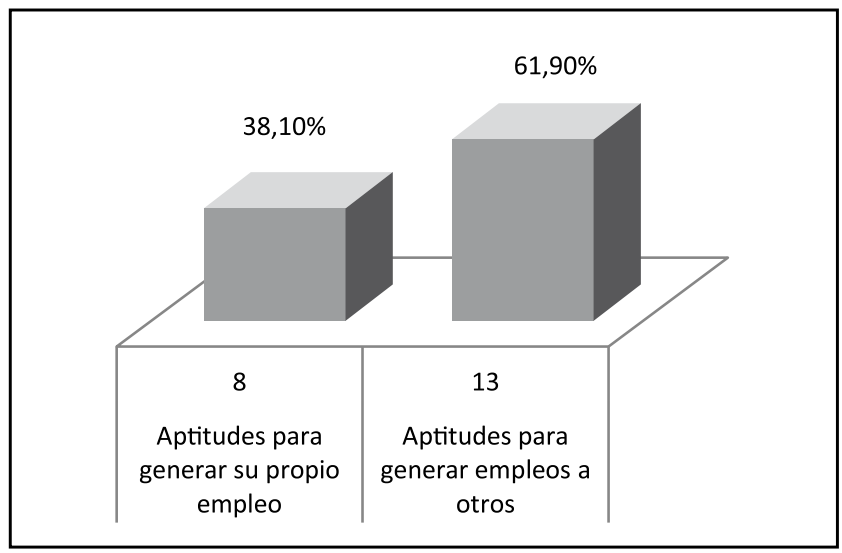

Fuente adaptado del GEM Colombia Caribe 2010, Elaboración autoras.

Teniendo en cuenta que las nuevas empresas así como las pequeñas y medianas empresas - Pymes, constituyen una fuente de empleo y activación permanente de la economia regional (17). Esta fue la actitud que estuvo presente en los emprendedores, los cuales no solo buscaban su autoempleo, sino el de otras personas.

FIGURA No. 12. PERCEPCIÓN DE GESTIÓN, RIESGO, Y ESTATUS

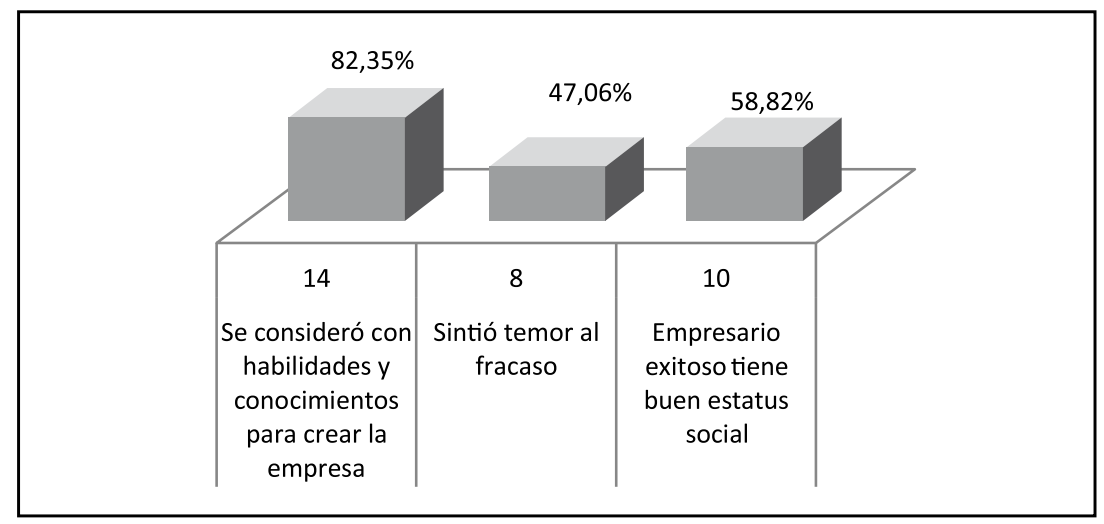

Fuente adaptado del GEM Colombia Caribe 2010, Elaboración autoras. 
Esto refleja la actitud emprendedora (17) presente en cada uno de ellos, en la cual se consideraban con los fundamentos y conocimientos para la creación y administración de la empresa, así como el nivel de riesgo al cual quedaban expuestos una vez aceptaran los recursos del fondo emprender.

FIGURA No. 13. OTRAS PERCEPCIÓN

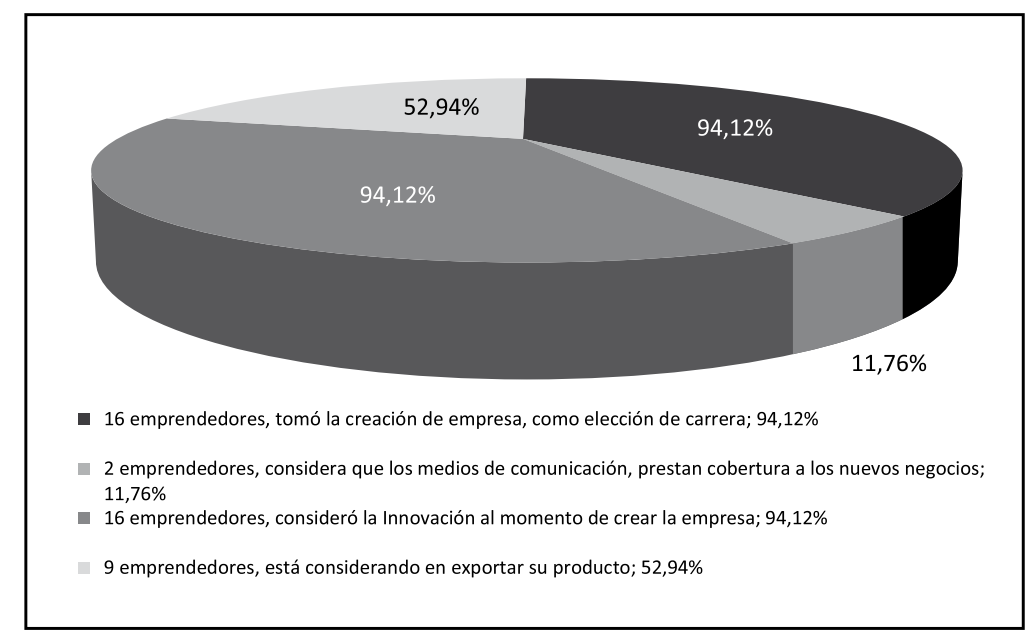

Fuente adaptado del GEM Colombia Caribe 2010, Elaboración autoras.

La innovación de productos y procesos, la internacionalización y los deseos por procurar altos niveles de crecimiento son consideradas el sello del emprendimiento (17).

Después de recopilar y analizar los resultados de la encuesta realizada, se puede concluir que la caracterización de los emprendedores del Fondo Emprender en Sincelejo, presentan el siguiente perfil:

- El rango de edad potencial está entre 25 y 30 años.

- La mayoría corresponden al género masculino.

- La creación se constituye entre el 2008 y el 2010.

- Existe un incremento de nuevos emprendedores.

- Muy pocos se encuentran dedicados de forma exclusiva a su negocio, por lo poco rentable o porque buscan incrementar sus ingresos mensuales.

- Los ingresos mensuales de los emprendedores se ubica entre 2 y 3 SMMLV.

- La oportunidad fue la motivación para crear la empresa.

- Un alto porcentaje tiene formación en pregrado. 
- Algunos contaron con la asesoría de una persona cercana.

- Casi todos se percibían con las habilidades y conocimientos para manejar la empresa.

- Muy pocos sintieron temor al fracaso, porque son tomadores de riesgos.

- Todos, a excepción de uno, consideraron la innovación en el producto o servicio ofrecido, por lo cual les permite considerar en la exportación de ellos.

- Todos, a excepción de uno, concibió la creación de empresa, como su elección de carrera.

- Un sentir general, fue que los medios de comunicación prestan poca atención a los nuevos emprendedores.

\section{CONTRASTACIÓN ENTRE RESULTADOS DE LA ENCUESTA $Y$ EL GEM COLOMBIA CARIBE 2010}

De todos los enfoques presentados en el marco teórico, el más completo, preciso y confiable es el propuesto por la organización Global Entrepreneurship Monitor - GEM, en el cual un equipo de expertos rinde la evaluación anual sobre las actividades empresariales, las aspiraciones y actitudes de los individuos a través de una amplia gama de países. Este estudio, es el más grande de la dinámica emprendedora en el mundo, revelando las características detalladas y relacionadas con la actividad empresarial (59).

\section{¿Qué es el GEM y su importancia?}

El GEM es el estudio más grande en curso de la dinámica emprendedora en el mundo, explora el papel del empresariado en el crecimiento económico nacional, revelando las características detalladas y las características nacionales relacionados con la actividad empresarial. Los datos recogidos son 'armonizados' por un equipo central de expertos, lo que garantiza su calidad y facilidad para realizar las comparaciones entre países (59).

En él, se evalúa de forma anual las actividades empresariales, las aspiraciones y actitudes de los individuos a través de una amplia gama de países, monitoreando la actividad de creación de empresas en los países que de él hagan parte. Este proyecto inició en 1999, como una asociación entre la London Business School y el Babson College. El primer estudio se realizó con 10 países, y desde entonces más de 85 'equipos nacionales' de todos los rincones del mundo, han participado en el proyecto, que sigue creciendo cada año. 


\section{Aportes del GEM al presente trabajo}

Teniendo en cuenta lo complejo y variado que es el fenómeno del emprendimiento para definir el perfil de los emprendedores, y las variadas tendencias y modelos que han desarrollado diversos autores (52), el GEM proporciona una información puntual de la caracterización de Sincelejo. En él, se consideró el contexto del país, ciudad y región, por tanto es una herramienta de gran utilidad.

El GEM goza de un alto prestigio a nivel internacional, sus informes han sido objeto de estudio por diversos investigadores $(12 ; 17 ; 52 ; 58)$. Todo esto, fundamenta la decisión de ser elegida entre los otros postulados presentados, para efectuar la validación de los resultados obtenidos en la encuesta aplicada.

\section{Contrastación de la información}

Esta se realiza mediante un paralelo entre la caracterización presentada por el GEM y los resultados obtenidos en la encuesta:

FIGURA No. 14. GÉNERO

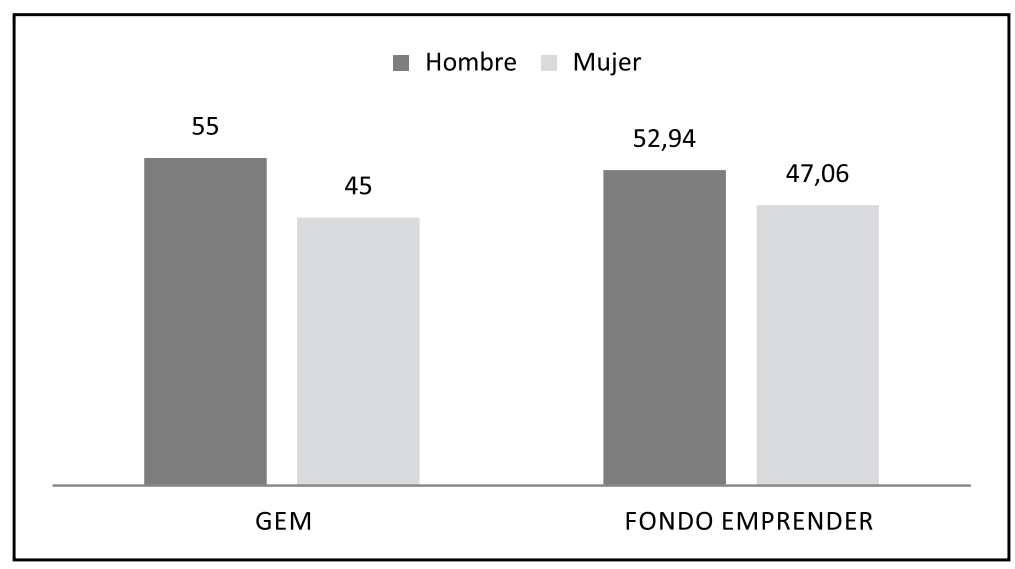

Fuente Elaboración autoras.

Se observa una pequeña ventaja de los hombres hacia las mujeres. Estudios han comprobado que a mediano y largo plazo, esto tiende hacia la igualdad en la nueva actividad empresarial entre hombres y mujeres, debido a que la mujer ha asumido un nuevo rol en la sociedad colombiana, donde desempeña funciones como jefe de hogar, madre, empresaria y líder social, realizando labores de emprendimiento que le permiten subsistir a ella y su núcleo familiar (52). 
FIGURA No. 15. EDAD

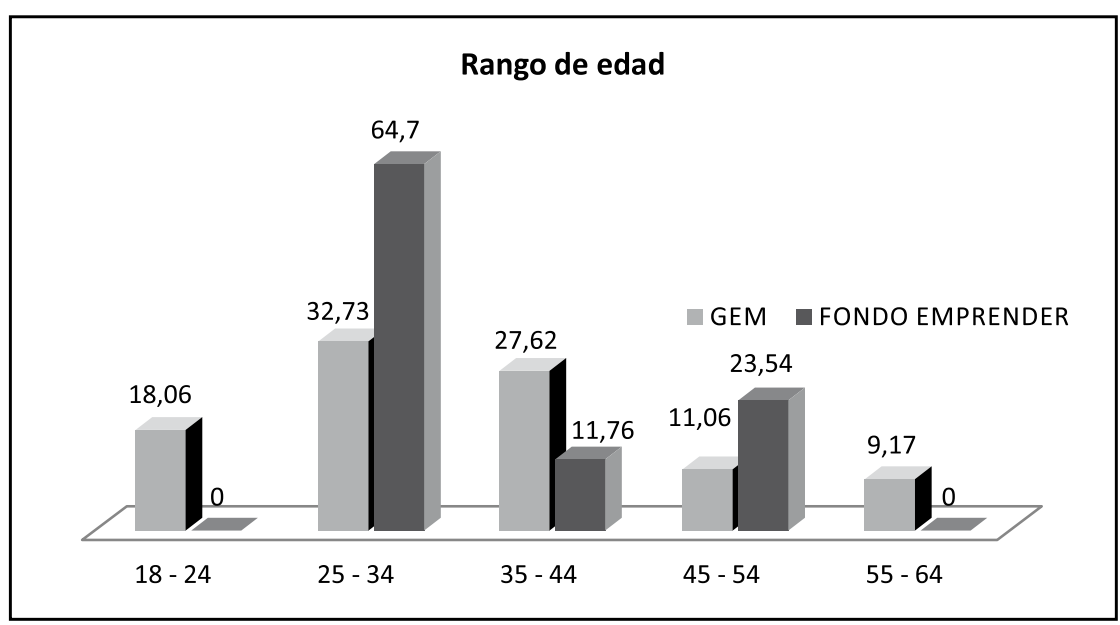

Fuente Elaboración autoras.

El rango más emprendedor se encuentra entre los 25 a 34 años, debido a su dinamismo en el campo de la Población Económicamente Activa y su aporte a la economía por su creatividad e innovación en la creación de nuevas empresas (52).

FIGURA No. 16. FORMACIÓN EDUCATIVA

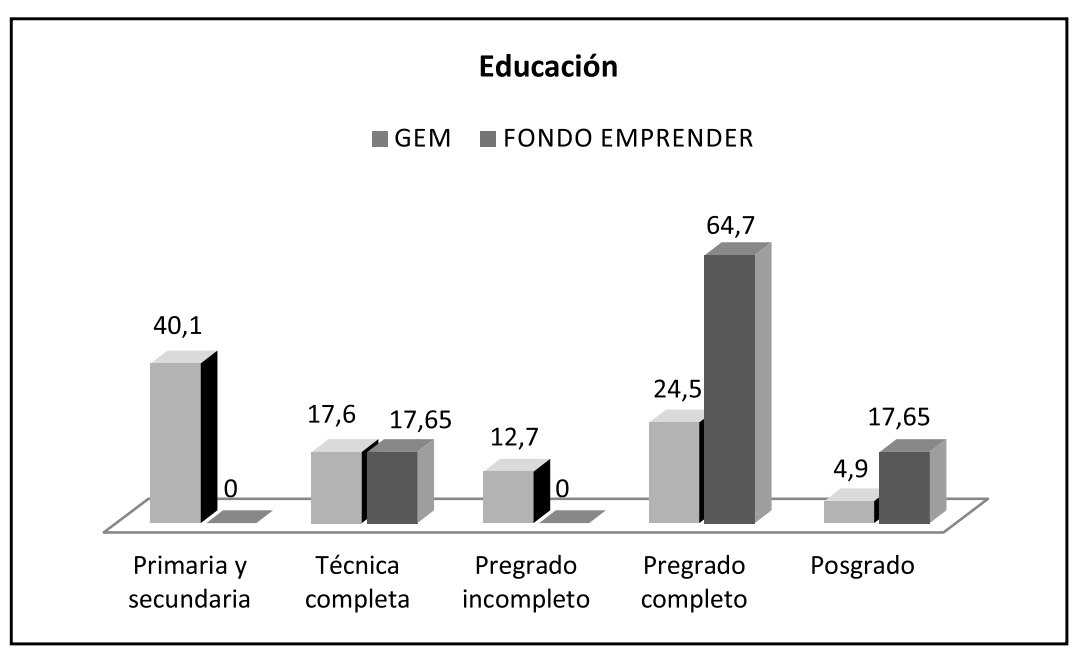

Fuente Elaboración autoras.

El nivel educativo es una variable determinante en la calidad del emprendimiento por oportunidad, reflejada en el nivel de ingresos de los empresarios. Los profesionales universitarios son los que reportan mayor índice de emprendimiento, dado los requisitos del Fondo (52). 
FIGURA No. 17. INGRESO MENSUAL

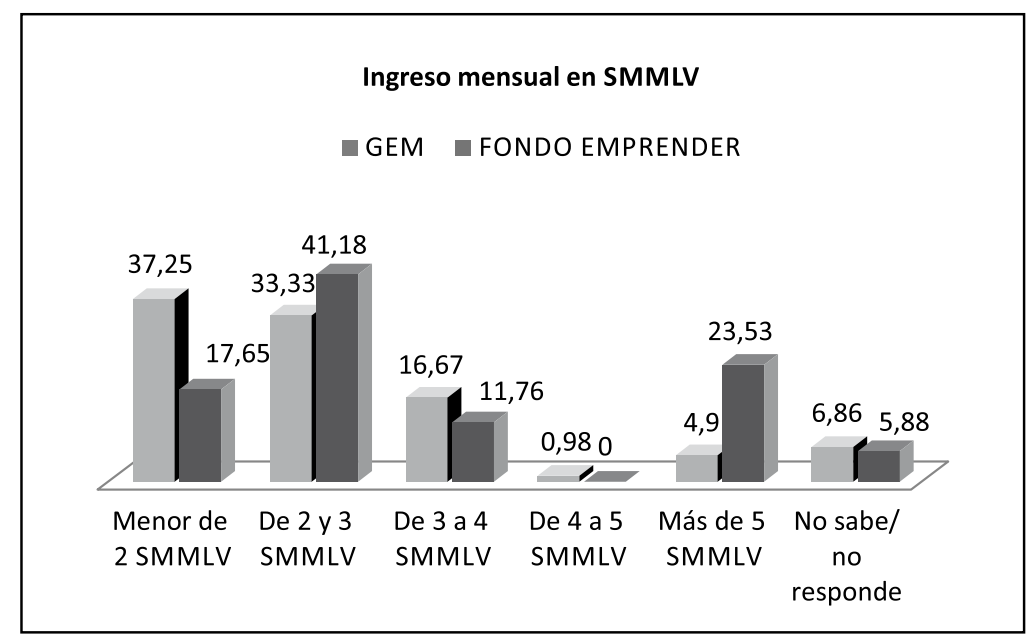

Fuente Elaboración autoras.

Los empresarios establecidos perciben mayores ingresos que los empresarios nacientes y nuevos (52), lo cual en el análisis de ingresos va a reflejar una pequeña porción con altos ingresos y el resto con ingresos igual y menores a 3 salarios mínimos.

FIGURA No. 18. CONOCIÓ A ALGUIEN

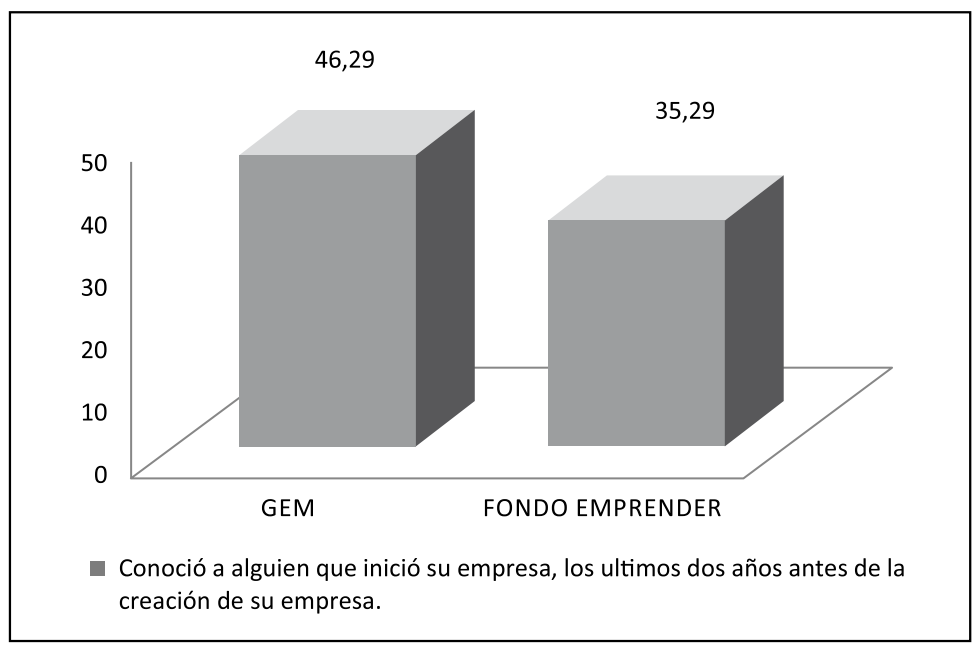

Fuente Elaboración autoras.

Los antecedentes empresariales, aportan y constituyen la experiencia por la cual el emprendedor desarrolla su capacidad con el entorno empresarial (52). Para el caso de emprendedores Fondo Emprender, prevalecieron 
otros factores e influencias en el entorno, antes que conocer a alguien los últimos dos años antes de crear la empresa.

\section{FIGURA No. 19. INFLUENCIA SOBRE LA CREACIÓN DE LA EMPRESA}

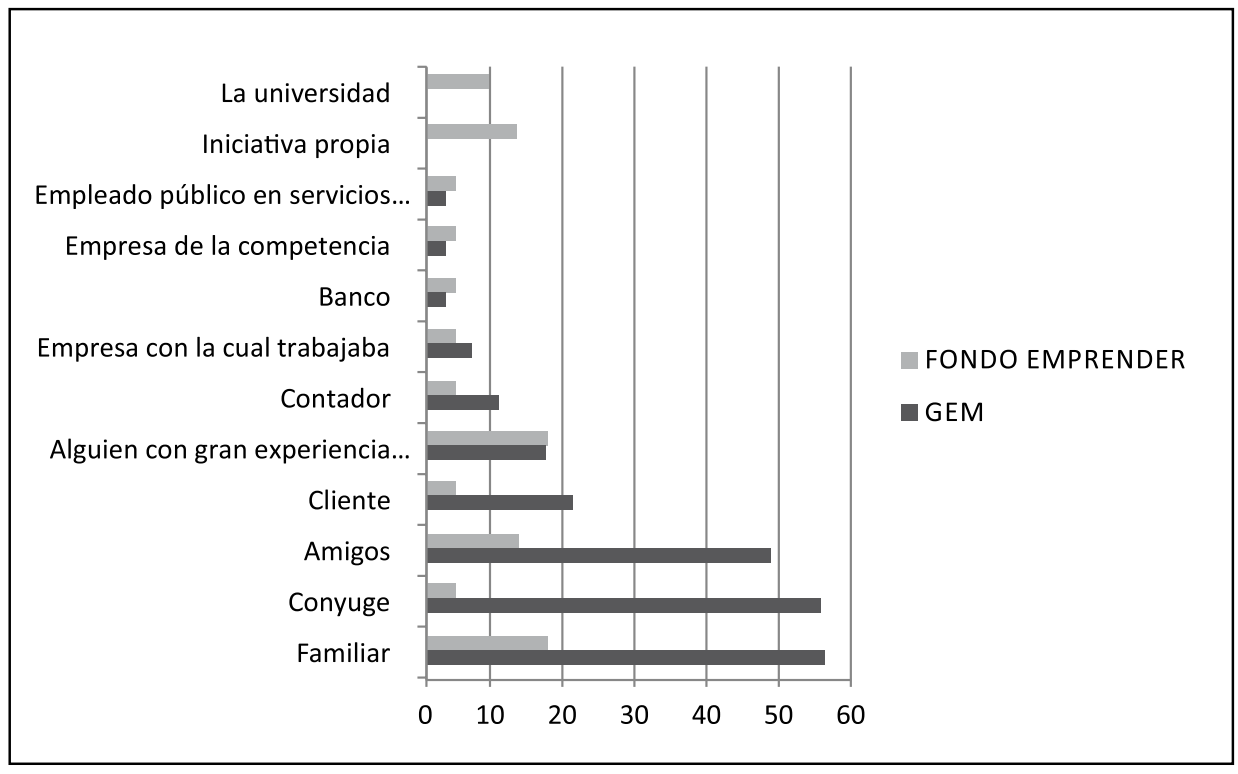

Fuente Elaboración autoras.

Aunque existen múltiples factores que inciden en la decisión de crear una empresa, estudios han demostrado la influencia de la formación empresarial en los establecimientos educativos (53), lo cual confirma que el emprendimiento puede ser aprendido (36).

FIGURA No. 20. MOTIVACIÓN

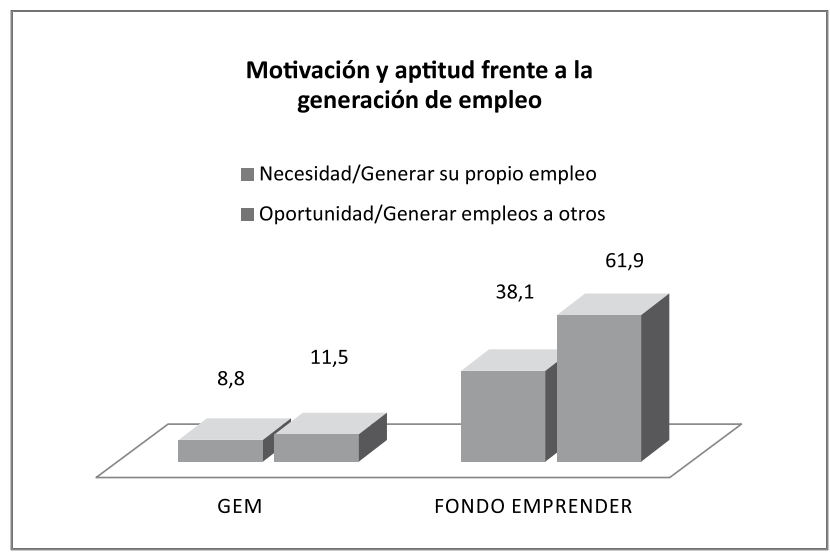

Fuente Elaboración autoras. 
La principal motivación para la creación de empresa fue la oportunidad, donde se evidencia la creatividad y la innovación tecnológica como parte de la cultura empresarial (52).

\section{FIGURA No. 21. PERCEPCIÓN DE LAS HABILIDADES, RIESGOS, Y ESTATUS}

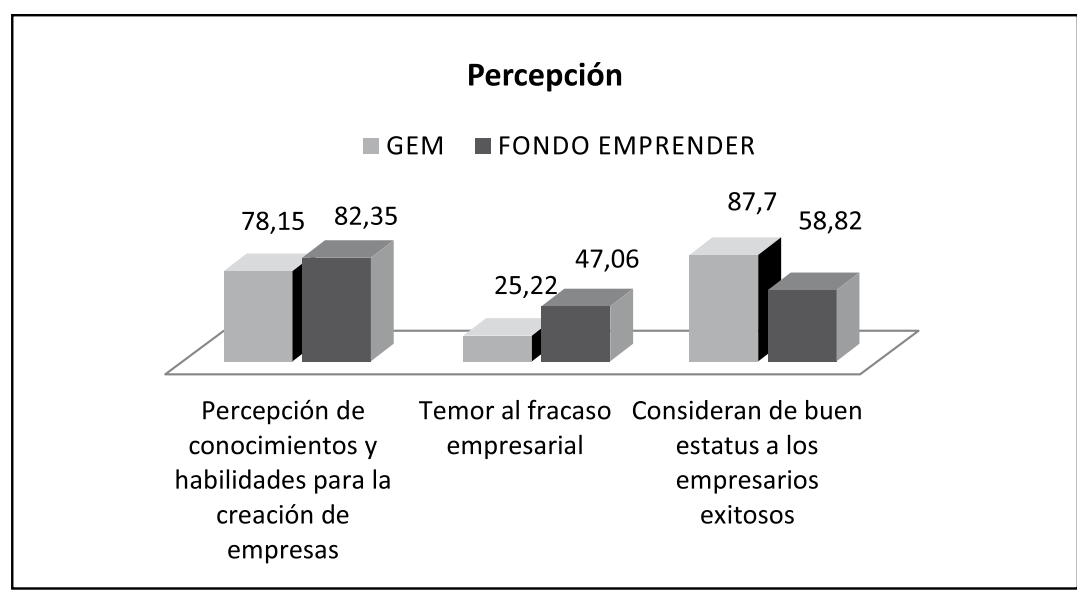

Fuente Elaboración autoras.

Es importante que el emprendedor reconozca las oportunidades de negocio valiosas, y que perciban en sí mismas la existencia de habilidades requeridas para explotar dichas oportunidades (17).

\section{FIGURA No. 22. OTRAS PERCEPCIONES}

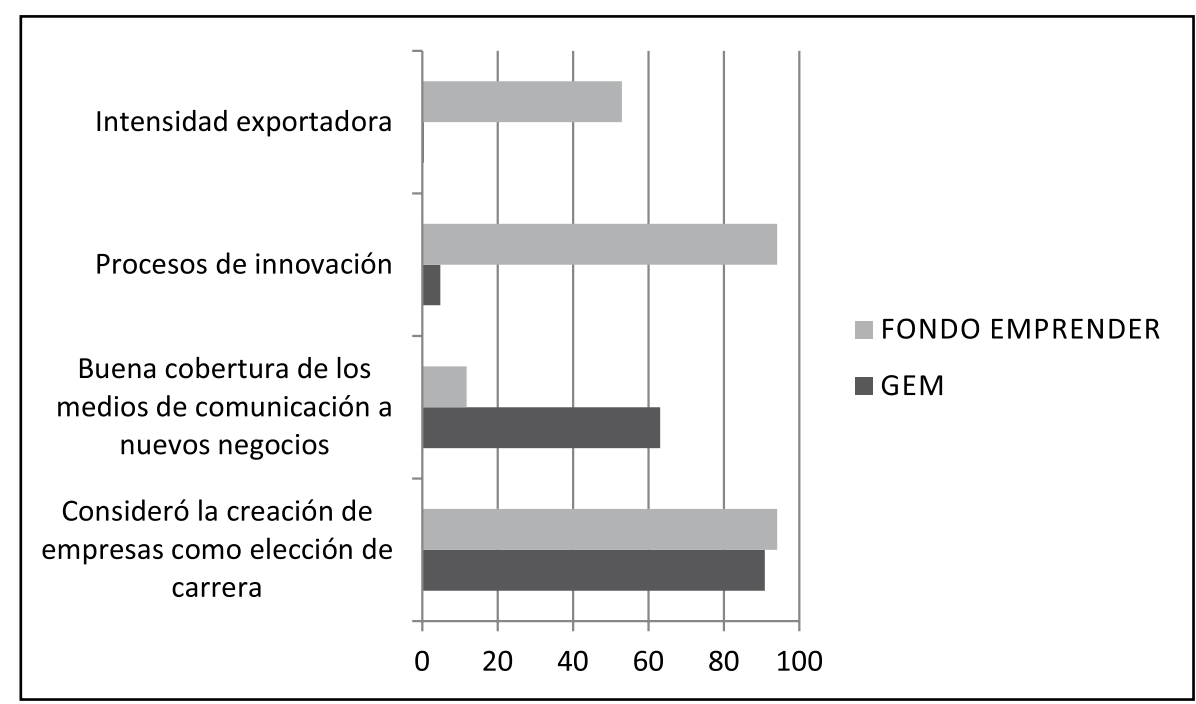

Fuente Elaboración autoras. 
Existe una gran percepción de asegurar su futuro económico a través de la creación de empresas, ofreciendo innovación y creatividad en los productos y procesos (52).

\section{Conclusiones y recomendaciones}

El emprendimiento es un campo de investigación en construcción y legitimación, a pesar del esfuerzo y aportes realizados por los eruditos para ganar validez y constituirse en conocimiento científico. Pero esto requiere la participación de más investigadores dispuestos a crear un cuerpo de teorías sistemáticas, que le den el fundamento que necesita esta disciplina.

No es posible pensar en que se va a realizar un perfil de éxito, que será aplicable a todos, y en todos produzca el mismo resultado, este es el avance de las escuelas de pensamiento, las cuales han superado el tema de rasgos físicos o psicológicos, para hablar de actitudes, conducta, y comportamiento en el contexto donde se encuentre.

Por su parte, la contrastación que valida el resultado obtenido de la encuesta con lo reportado por el GEM, confirma los siguientes aspectos:

- Hay más emprendedores con género masculino.

- Los emprendedores potenciales se encuentran en un rango de 18 a 35 años de edad.

- Se coincide al afirmar que la gran mayoría conoció a una persona que la inspiró a crear su propia empresa. Aunque algunos afirmaron, que surgió de la iniciativa propia o en la Universidad, situaciones que no estaban contempladas en el reporte GEM.

- Es afirmada la oportunidad como motivación en la creación de la empresa.

- La percepción de poseer habilidades y conocimientos para emprender la empresa, fue confirmada por los resultados.

- Ambos confirman, que la creación de empresas es considerada como una elección de carrera.

De este mismo modo, se aprecian algunas diferencias en los resultados, motivados por el contexto y la población a la cual se dirigió el presente estudio, como se describe a continuación:

- Por los requisitos establecidos en el Fondo Emprender, no es posible encontrar emprendedores con un nivel de formación de primaria o 
básica secundaria, el cual es la mayoría en el reporte del GEM.

- Dada la formación Técnica y Universitaria que tienen los Emprendedores del Fondo Emprender, les permite obtener ingresos adicionales a su negocio, por lo cual los niveles de ingresos muestran una diferencia notoria. Esto se confirma con el hecho, que no están dedicados de forma exclusiva a su negocio.

- El temor al fracaso se sintió más en los emprendedores del Fondo Emprender.

- Los emprendedores del GEM, consideran que los empresarios exitosos gozan de reconocimiento y prestigio social.

- En el informe del GEM, los medios de información ofrecen cobertura a negocios de nuevos emprendedores, mientras que los emprendedores del Fondo Emprender no lo ven de esta forma, que para ello se debe pagar la publicidad.

- La innovación en el producto como la exportación, representa un punto importante para los emprendedores del Fondo Emprender.

No fue posible validar el nivel de formación, los ingresos mensuales, el temor al fracaso, el nivel de status social de los empresarios reconocidos, la cobertura de los medios de comunicación, y la innovación en los productos. Lo anterior es razonable, si se tiene en cuenta que son profesionales la mayoría de emprendedores del Fondo Emprender, lo cual le permite tener una visión diferente de la creación de empresa, no siendo así los emprendedores encuestados por el GEM, que en la gran mayoría su formación era primaria y secundaria.

Se puede concluir que el instrumento utilizado fue adecuado, debido a que permitió cotejar de forma apropiada la información, y analizar las diferencias presentadas, lo cual se justifica por la población objeto de estudio: Pero, de manera general, la investigación arrojo resultados muy acordes a los ya presentados por el GEM.

Para finalizar, se recomienda a todos los interesados en el tema de emprendimiento, desarrollar y profundizar investigaciones teóricas, que permitan al emprendimiento legitimar y validarse entre las otras ciencias. También se sugiere, no buscar y diseñar recetas mágicas que tengan como fin desarrollar empresarios exitosos, tal receta no existe, porque las reacciones de cada persona frente a la misma oportunidad son diferentes. Se espera que este trabajo haya generado nuevos aportes en la disciplina del emprendimiento. 


\section{REFERENCIAS BIBLIOGRÁFICAS}

1. Ministerio de Comercio, Industria y Turismo. Ley 1014 de 2006. De Fomento a la Cultura del Emprendimiento. Bogotá D.C.: Diario Oficial del Estado No.46164 (27-01-2006), 2006.

2. Shane S., Venkataraman S. The Promise of Entrepreneurship as a Field of Research. The Academy of Management Review. 2000. Vol. 25, 1, págs. 21-226.

3. Gibbs A. (1987), Enterprise Culture: It's Meaning and Implication for Education and Training. Journal of European Training, M.C.B. Publications, Spring 1987. Citado por Varela, 2001 en Innovación Empresarial: Arte y ciencia en la creación de empresas (2da Ed). Bogotá D.C.: Pearson Educación de Colombia Ltda.

4. Timmons J. (1990), New venture creation: entrepreneurship in the1990s (3rd Ed). Boston: Irwin. Citado por Ocampo, 2008 en Aproximación conceptual a la preparación en emprendimiento. s.l.: Revista Eos. Vol. 2, págs. 33-53.

5. Timmons J. (1999), New venture creation: entrepreneurship for the 21st Century. Boston: Irwin Mc Graw Hill. Citado por Varela, 2001 en Innovación Empresarial: Arte y ciencia en la creación de empresas (2da Ed). Bogotá D.C.: Pearson educación de Colombia Ltda.

6. Dávila C. Teorías organizacionales y administrativas (2da Ed). Bogotá D.C.: Mc Graw Hill, 2001.

7. Thornton, P. The Sociology of Entrepreneurship. Annual Review of Sociology, 1999. Vol. 25, págs. 19-46.

8. Lounsbury M., Glynn M. Cultural Entrepreneurship: Stories, Legitimacy, and the Acquisition of Resources. s.l.: Strategic Management Journal, 2001. Vol. 22, págs. 545-564.

9. Díaz J, Urbano D., Hernández R. Teoría Económica Institucional y creación de Empresas. Revista Investigaciones Europeas de Dirección y Economía de la Empresa, 2005. Vol. 11, 3, págs. 209-230.

10. Aktouf O. La Administración entre tradición y renovación (4ta Ed). Cali: Artes graficas del Valle, 2009. 
11. Varela, R. Innovación Empresarial: Arte y ciencia en la creación de empresas (2da Ed). Bogotá D.C.: Pearson educación de Colombia Ltda, 2001.

12. Reynolds P., Bosma N., Autio E., Hunt S., De Bono N., Servais I., et al. Global Entrepreneurship Monitor: Data Collection Design and Implementation 1998-2003. Small Business Economics. 2005, Vol. 24, págs. 205-231.

13. Moncayo, P. Emprendimiento: un concepto que integra el ser y el hacer del sujeto. Management Revista de la Facultad de Ciencias Empresariales. 2008, Vol. 17, 29, págs. 33-48.

14. Mello A, Barros D., Felicio J. A Dimensão Histórica dos Discursos acerca do Empreendedor e do Empreendedorismo. RAC, Curitiba. 2011, Vol. 15, 2, págs. 179-197.

15. Vera M., Mora E. Líneas de investigación en micro, pequeñas y medianas empresas. Revisión documental y desarrollo en Colombia. Tendencias. 2011, Vol. 12, 1, págs. 213-226.

16. Shapero, A. Why entrepreneurship? A world wide perspective. Journal of Small Business Management, Guest Editorial. 1985, págs. 1-5.

17. Amorós, J. El Proyecto Global Entrepreneurship Monitor (GEM): Una Aproximación Desde el Contexto Latinoamericano. Revista Latinoamericana de Administración. 2011, Vol. 46, págs. 1-15.

18. Sanchez J., Gutierrez A. Entrepreneurship research in Spain: Developments and distinctiveness. Psicothema. 2011, Vol. 23, 3, págs. 458-463.

19. Gartner, W. A Conceptual Framework for Describing the Phenomenon of New Venture Creation. The Academy of Management Review. 1985, Vol. 10, 4, págs. 696-706.

20. Stevenson H., Jarillo J. A Paradigm of Entrepreneurship: Entrepreneurial Management. Strategic Management Journal. 1990, Vol. 11, págs. 17-27.

21. Bygrave W., Hofer C. Theorizing about entrepreneurship. Entrepreneurship Theory and Practice. 1991, Vol. 16, 2, págs. 13-22. 
22. Cable D., Shane S. A Prisoner's Dilemma Approach to EntrepreneurVenture Capitalist Relationships. The Academy of Management Review. 1997, Vol. 22, 1, págs. 142-176.

23. Zahra S., Nambisan S. Entrepreneurship in global innovation ecosystems. Academy of Marketing Science Rev. 2011, Vol. 1, págs. 4-17.

24. Matiz,F.Investigación en emprendimiento, un reto para la construcción de conocimiento. Revista EAN. 2009, Vol. 66, págs. 169-182.

25. Murphy, P. Entrepreneurship theory and the poverty of historicism. Journal of Management History. 2009, Vol. 15, 2, págs. 109-133.

26. Ronstadt, R. The Educated Entrepreneurs: A New Era of Entrepreneurial Education is Beginning. American Journal of Small Business. 1987, Vol. 10, 1, págs. 37-53.

27. Nueno, P. Emprendiendo hacia el 2020: una renovada perspectiva global del arte de crear empresas y sus artistas. Barcelona: Deusto, 2009.

28. Grégoire D., Corbett A., McMullen J. The Cognitive Perspective in Entrepreneurship: An Agenda for Future Research. Journal of Management Studies. Journal of Management Studies, 2011, Vol. 48, 6, págs. 1443-1477.

29. Acs Z., AUDRETSCH D. Handbook of Entrepreneurship Research, International Handbook Series on Entrepreneurship. Second Edition. Springer New York. 2003. [En línea] [Citado el: 24 de Enero de 2012.] Disponible en: http://books.google.com.au/books?id=4KRnkLZfXt MC\&printsec $=$ frontcover\&hl=es\&source=gbs_ge_summary_r\&cad= $0 \# \mathrm{v}=$ onepage $\& \mathrm{q} \& \mathrm{f}=$ false.

30. Kent, C. The Treatment of Entrepreneurship in Principles of Economics Textbooks. The Journal of Economic Education. 1989, Vol. 20, 2, págs. 153164.

31. Van C., Versloot P. What is the value of entrepreneurship? A review of recent research. Small Bus Econ. 2007, Vol. 29, págs. 351-382.

32. Kuskova V., Podsakoff N., Podsakoff P. Effects of theoretical contribution, methodological rigor, and journal quality, on the impact 
of scale development articles in the field of entrepreneurship. Strategic Entrepreneurship Journa. 2011, Vol. 5, págs. 10-36.

33. Gartner, W. "Who is an entrepreneur" is the wrong question. American Journal of Small Business. 1988, Vol. 13, págs. 11-31.

34. Kirzner, I. Competition and Entrepreneurship. The University of Chicago Press, Ltd. 1973.

35. Flor G., Lara A. Diagnóstico del capital emprendedor y su influencia en la creación de empresas y desarrollo socioeconómico en la región sierra-centro del ecuador. Quito: Memoria del XXII Congreso Latinoamericano sobre Espíritu Empresarial, 2012.

36. Castillo, A. Estado del arte en la enseñanza del emprendimiento. Chile: Programa Emprendedores como creadores de riqueza y desarrollo regional INTEC Chile, 1999.

37. Formichella, M. El concepto de emprendimiento y su relación con la educación, el empleo y el desarrollo local. Buenos Aires, Argentina: Publicación INTA, 2004.

38. González J., Cerón C., Alcazar F. Caracterización emprendedora de los empresarios en los Valles de Tundama y Sugamuxi. Boyacá (Colombia). Pensamiento \& gestión. 2010, Vol. 29, págs. 163-189.

39. Valdaliso J. López S. Historia económica de la empresa. Barcelona: Crítica, 2000.

40. Zorrilla, J. Las etapas del empresario moderno. Argentina: El Cid Editor apuntes, 2009.

41. Shane S., Locke E., Collins C. Entrepreneurial motivation. Human Resource Management Review. 2003, Vol. 13, págs. 257-279.

42. Rodríguez C., Jiménez, M. Emprenderismo acción gubernamental y academia. Revisión de la literatura. Innovar. 2005, Vol. 15, 26, págs. 73-89.

43. Gámez, J. El emprendedor; hacía una nueva caracterización en Colombia. Management Revista de la Facultad de Ciencias Empresariales. 2008, Vol. 17, 29, págs. 17-32. 
44. Kirzner, I. Entrepreneurial Discovery and the Competitive Market Process: An Austrian Approach. Journal of Economic Literature. 1997, Vol. 35, 1, págs. 60-85.

45. Schumpeter J. Capitalis, Socialism and Democracy (3th Ed). New York: Harper \& Row, Publishers, 1950.

46. Kirzner, I. Creativity and/or Alertness: A Reconsideration of the Schumpeterian Entrepreneur. Review of Austrian Economics. 1999, Vol. 11, págs. 5-17.

47. Ocampo, J. Aproximación conceptual a la preparación en emprendimiento. Revista Eos. 2008, Vol. 2, págs. 33-53.

48. Mccaffrey, M. Entrepreneurship, economic evolution, and the end of capitalism: reconsidering schumpeter's thesis. The quarterly journal of austrian economics. 2009, Vol. 12, 4, págs. 3-21.

49. Goss, D. Schumpeter's Legacy? Interaction and Emotions in the Sociology of Entrepreneurship. Entrepreneurship Theory and Practice. 2005, Vol. 29, págs. 205-218.

50. Shaver K., Scott L. Person, Process, Choice: The psychology of new venture creation. Entrepreneurship: Theory and Practice. 1991, Vol. 16 , 2, págs. 23-45.

51. Global Entrepreneurship Monitor, GEM. Reporte de resultados GEM Colombia Caribe 2010. Bogotá D.C.: Editorial Universidad del Norte, 2010. ISBN 978-958-741-141-6.

52. Rodríguez, A. El emprendimiento en Colombia. Entramado. 2008, Vol. 4, 2, págs. 20-37.

53. Arraut L., Novoa K, Sánchez H. Caracterización de los egresados empresarios de la universidad tecnológica de bolívar como estrategia de universidad empresarial. Cali: Memorias XXI Congreso Latinoamericano sobre Espíritu Empresarial, 2011.

54. Departamento Administrativo Nacional de Estadísticcas, DANE. Gran Encuesta Integrada de Hogares - Octubre 2010. [En línea] [Citado el: 13 de Noviembre de 2011.] Disponible en: http:/ / www.dane.gov.co/ files/investigaciones/boletines/ech/ech/bol_ech_oct10.pdf. 
55. Ministerio de Comercio, Industria y Turismo. Informe del perfil económico por departamento. [En línea] [Citado el: 13 de Noviembre de 2011.] Disponible en: https://www.mincomercio.gov.co/ publicaciones.php?id=16724.

56. Ley 1450 de 2011. Por la cual se expide el Plan Nacional de Desarrollo 2010 - 2014. Bogotá D.C.: Diario Oficial del Estado No. 48102 (16-062011), Capítulo 3, Art. 2. págs. 50-178.

57. Fondo Emprender. [En línea] [Citado el: 16 de Octubre de 2011.] Disponible en: http://www.fondoemprender.com/ BancoConocimiento/R/Resulta dos_Convocatorias_Nacionales/ Resultados_Convocatorias_Nacionales.asp?CodSeccion=1.

58. Arenius P., Minniti M. Perceptual Variables and Nascent Entrepreneurship. Small Business Economics. 2005, Vol. 24, págs. 233-247.

59. Global Entrepreneurship Monitor GEM. [En línea] [Citado el: 13 de Noviembre de 2011.] Disponible en: http://www.gemconsortium. org/What-is-GEM. 
